Laboratoire de Recherche en Gestion $\&$ Economie

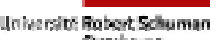

Shritsote

\title{
LARGE
}

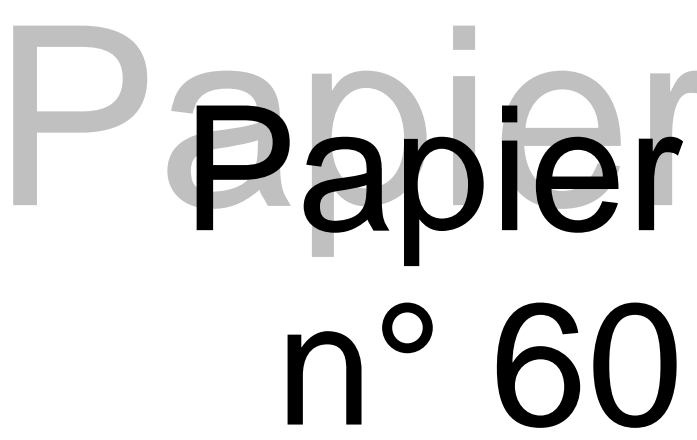

Monetary policy in the presence

of asymmetric wage indexation

Faculté des sciences économiques et de gestion

Juillet 2003

Giuseppe Diana - Pierre-Guillaume Méon

61, avenue de la Forêt Noire 67085 STRASBOURG Cedex

Tél. : (33) 0390242152

Fax : (33) 0390242151

www-ulp.u-strasbg.fr/large 


\section{Monetary policy in the presence of asymmetric wage indexation}

July 2003

\author{
Giuseppe Diana \\ BETA-theme, Université Louis Pasteur \\ GRICE-TIPEE, Université Robert Schuman \\ Pole Européen de Gestion \\ 61, avenue de la Forêt Noire \\ 67085 Strasbourg Cedex, France \\ Phone : (33) 390242165 \\ Fax: (33) 390242071 \\ e-mail:diana@cournot.u-strasbg.fr
}

\author{
Pierre-Guillaume Méon* \\ LARGE \\ Institut d'Etudes Politiques \\ Université Robert Schuman \\ 47, avenue de la Forêt Noire \\ 67082 Strasbourg Cedex, France \\ Phone: (33) 388417721 \\ Fax: (33) 388417778 \\ e-mail : pierre-guillaume.meon@iep.u-strasbg.fr
}

Abstract: We study optimal monetary policy in the presence of asymmetric wage indexation. We find that the monetary authorities do not react to small output shocks and that their reaction to large shocks is asymmetric, insofar as they absorb positive shocks more than negative ones. As a consequence, we observe that asymmetric wage indexation can be recessionary and that it decreases the inflationary bias relative to an equivalent symmetric indexation.

Key words: monetary policy, wage indexation.

JEL classification: E30, E50, E61, J30.

\footnotetext{
* Corresponding author.
} 


\section{Monetary policy in the presence of asymmetric wage indexation}

July 2003

Abstract: We study optimal monetary policy in the presence of asymmetric wage indexation. We find that the monetary authorities do not react to small output shocks and that their reaction to large shocks is asymmetric, insofar as they absorb positive shocks more than negative ones. As a consequence, we observe that asymmetric wage indexation can be recessionary and that it decreases the inflationary bias relative to an equivalent symmetric indexation.

Key words: monetary policy, wage indexation.

JEL classification: E30, E50, E61, J30.

\section{Introduction}

The study of the reaction functions of central banks has attracted a lot of attention from both academics and practitioners over the recent years, leading to a flourishing literature that has accumulated fresh evidence. Among the fresher results stands the fact that monetary policy tends to be asymmetric. Namely, it is not adjusted in the same way in the presence of positive or adverse shocks. This observation initially made by Mishkin and Posen(1997) and Clarida and Gertler (1997) was later confirmed by Dolado et al. (2000). It thus appears that major central banks tend to react more aggressively when inflation exceeds its target level than when it is below it.

This finding is clearly at odds with most of the theoretical work on monetary policy, which, in the spirit of Barro and Gordon (1983), usually assumes that symmetric central banks with symmetric preferences face symmetric economies. To depart from the perfect symmetric world that is usually depicted in theoretical contributions, and provide a rationale for observed stylized facts, some authors explicitly introduced an asymmetry in the preferences of the monetary authority. Thus, the recent papers by Dolado et al. (2000), Gerlach(2000), Cukierman (2000), Jordan (2001), or 
Cukierman and Gerlach (2002) all assume that the monetary authorities' loss function is asymmetric. Namely, they assume that positive and negative deviations of economic variables from their target levels impact differently on the central banker's utility.

Asymmetric preferences is however not the only asymmetry that may interfere with the conduct of monetary policy. In fact monetary authorities are confronted with many asymmetries, the most obvious of which being the economy itself. Thus, Cover (1992) observes that negative monetary growth shocks in the United States induce large contractions in real output growth whereas positive monetary shocks have only limited expansionary consequences. Kandil (1995, 1998, 2002) also repeatedly observed similar asymmetries in various samples of countries both developed and developing.

A likely culprit for those asymmetries is wage indexation, since wages are typically indexed upward but not downward. Such an observation was for instance made by Card (1986) for North American wages. Moreover, Kandil $(1995,1998)$ observed asymmetric reactions of nominal wages to monetary shocks at the aggregate level. In a more recent paper Kandil (2002) studies the evolution of the United States' performance in the light of the variations in the downward rigidity and upward flexibility of nominal wages. Those empirical observations were recently complemented by Cover and VanHoose (2002)'s contribution. These authors show that asymmetric wage indexation can be the result of a rational behavior of the private sector. Namely, they show that the private sector can choose to index nominal wages upward but not downward.

In this paper we also tackle the issue of asymmetric wage indexation from a theoretical point of view. However, instead of focusing on the explanation of that phenomenon, we concentrate on its consequences for monetary policy. Our paper therefore complements the literature devoted to the impact of wage indexation on monetary policy, that was pioneered by Ball and Cecchetti (1991), Vanhoose and Waller (1991, 1992) or Milesi-Ferretti(1994). That literature shows that wage indexation can be welfare enhancing because, even though it may raise the variability of output in the presence of real shocks, it cuts down the inflationary bias of monetary policy. Surprisingly it has only focused on symmetric wage indexation. Due to the policy implications of that strand of research, it is important to check the robustness of its results in the light of a more realistic framework. This is the aim of the present paper.

We find that the assumption of asymmetric wage indexation, although it leads to greater analytical complexity, significantly modifies the results of the literature. More precisely, we observe 
that the monetary authorities do not react to all output shocks and most of all that they adopt an asymmetric monetary policy rule. Accordingly, they tend to absorb expansionary shocks more than recessionary ones, which is in line with the stylized fact underlined above. That behavior can moreover result in an expected level of income that falls short of its natural level. We also find that asymmetric wage indexation lowers expected inflation, which is a standard result of the literature. However, we observe that it leads to lower average inflation than symmetric indexation. Finally, we find that it can raise welfare relative to both an equivalent symmetric wage indexation and a situation without indexation.

To reach those conclusions, the rest of the paper is organized as follows: the next section presents the simple set-up on which our reasoning rests. The following section describes the monetary authorities' behavior. Section 4 closes the model and compares the outcome of monetary policy in the presence of asymmetric wage indexation with the outcomes of monetary policy in the presence of symmetric wage indexation or no indexation. Section 5 concludes.

\section{The set-up}

To describe the supply side of our model, we suppose that output is a downward-sloping schedule of the real wage. When all variables are expressed in logs, the supply function reads:

$$
y_{t}=-\left(w_{t}-p_{t}\right)+u_{t}
$$

Where $y_{t}$ is output, $w_{t}$ the nominal wage, $p_{t}$ the price level. $u_{t}$ is a real shock, the magnitude of which is unknown to workers when they sign their wage contracts. $u_{t}$ is i.i.d. and has a zero mean and a well defined variance $\sigma_{u}{ }^{2}$. Expression (1) implicitly assumes that the natural level of output is zero.

The nominal wage is supposed to follow a modified Gray (1976) indexation rule. Namely, and following Cover and VanHoose (2002), we assume that wages are indexed upward but not downward. Therefore, the indexation rule reads:

$$
\begin{aligned}
& w_{t}=p_{t}^{e}+\delta\left(p_{t}-p_{t}^{e}\right) \\
& \text { where } 0 \leq \delta \leq 1 \text { if } p_{t}>p_{t}^{e} \text { and } \delta=0 \text { if } p_{t}=p_{t}^{e} .
\end{aligned}
$$

$\delta$ is the indexation parameter and $p_{t}^{e}$ the rationally expected price level. When the observed price level exceeds the expected price level, the nominal wage is therefore a weighted average of current and expected price levels. It is fully indexed when $\delta=1$. On the other hand, when the 
expected price level overshoots the observed price level, the nominal wage remains fixed. In other words, we assume that the nominal wage is automatically adjusted upward but is sticky downward. ${ }^{1}$

When (2) is plugged into (1), the supply function is transformed into an expectationsaugmented short-run Phillips curve:

$$
y_{t}=(1-\delta)\left(\pi_{t}-\pi_{t}^{e}\right)+u_{t}
$$

Where $\pi_{t}=p_{t}-p_{t-1}$ and $\pi_{t}^{e}=p_{t}^{e}-p_{t-1}$ are period $t$ 's current and rationally expected inflation. Expression (3) shows that the slope of the trade-off between income and unexpected inflation is a decreasing function of the indexation parameter $\delta$ whenever current inflation exceeds expected inflation. However, the slope of the supply curve is strictly greater when current inflation does not exceed or is equal to its expected level, as wages are not indexed downward. This means that the supply curve is kinked, which will have dramatic consequences on the behavior of the monetary authority, as we will see below.

To model the demand side, we simply assume that the inflation rate is set directly by a monetary authority whose loss function is similar to Barro and Gordon (1983)'s:

$$
l_{t}=\frac{\theta}{2} \pi_{t}^{2}+\frac{1}{2}\left(y_{t}-\bar{y}\right)^{2}
$$

$\bar{y}$ is the target level of output which can be greater than its natural level due, for instance, to distortions on the labor market. $\theta$ measures the relative weight the authorities place on inflation stabilization versus output stabilization.

To complete the description of our model, we must specify the timing of events. It is depicted in figure 1 below.

$* * *$ Insert figure 1 here***

We accordingly assume that workers sign their wage contracts at the beginning of period $t$. The value of the real shock $u_{t}$ is then revealed. The authorities subsequently set the inflation rate accordingly. Finally, production takes place.

\footnotetext{
${ }^{1}$ This is clearly a simplification. Our results would nevertheless remain qualitatively unchanged if we assumed
} 


\section{The authorities' reaction function}

When monetary policy is discretionary and players move sequentially, the only time consistent policy can be determined by backward induction. As workers play first we must therefore determine the authorities' reaction function for a given nominal wage.

When the authorities set the inflation rate, they have already observed the nominal wage, and the supply shock. Accordingly, they minimize the value of their loss function (4) subject to supply function (3) for a given level of $\pi_{t}^{e}$ and $u_{t}$. Taking the first order condition, we can determine an expression of the authorities' reaction function when the inflation rate exceeds its expected value: ${ }^{2}$

$$
\pi_{t}=\frac{(1-\delta)^{2} \pi_{t}^{e}+(1-\delta) \bar{y}-(1-\delta) u_{t}}{\theta+(1-\delta)^{2}} \quad \text { if } \pi_{t}>\pi_{t}^{e}
$$

One can immediately get an expression of the reaction function of the authorities when the price level is smaller than the expected inflation rate by setting $\delta=0$ in (5a). One consequently gets:

$$
\pi_{t}=\frac{\pi_{t}^{e}+\bar{y}-u_{t}}{\theta+1} \quad \text { if } \pi_{t}<\pi_{t}^{e}
$$

Of course, expressions (5a) and (5b) do not provide a complete description of the behavior of the authorities. We must indeed determine under which circumstances they will implement an inflation rate that is higher or lower than expected. In other words, we must determine the magnitude of the shock that will lead the authorities to set $\pi_{t}>\pi_{t}^{e}$ or $\pi_{t}<\pi_{t}^{e}$. To do so, we substitute $\pi_{t}$ by its value in (5a) and solve the resulting inequality for $u_{t}$. It then appears that the authorities will choose $\pi_{t}>\pi_{t}^{e}$ if (and only if) $u_{t}$ is strictly smaller than a trigger value $\underline{u}$ such that:

$$
\underline{u}=\bar{y}-\frac{\theta}{1-\delta} \pi_{t}^{e}
$$

By the same token, and using expression (5b), we find that the authorities will set $\pi_{t}<\pi_{t}^{e}$ if and only if $u_{t}$ is strictly smaller than a trigger value $\bar{u}$ such that:

$$
\bar{u}=\bar{y}-\theta \pi_{t}^{e}
$$

We assume that the parameters of the model are such that they result in a positive expected inflation. ${ }^{3}$ Since we assume that $\delta$ is smaller than one, it is clear that $\bar{u}>\underline{u}$. Therefore, if the reaction of the authorities is well defined for shocks smaller than $\underline{u}$ or greater than $\bar{u}$, we do not know yet

\footnotetext{
instead that wages are less indexed downward than upward.

${ }^{2}$ Note that $\pi_{t}>\pi_{t}^{e}$ is equivalent to $p_{t}>p_{t}^{e}$.

${ }^{3}$ It is in fact possible that expected inflation turns out negative as, as we will see below, the authorities tend to react more to positive output shocks that to negative ones. For realism's sake, we rule out that configuration.
} 
what their reaction may be in between. However, we demonstrate in appendix A1 that their best response whenever $u_{t} \in[u ; \bar{u}]$ is to set an inflation rate that is equal to the expected inflation rate.

We can now give a precise definition of the reaction function of the authorities. It reads:

$$
\pi_{t}= \begin{cases}\frac{(1-\delta)^{2} \pi_{t}^{e}+(1-\delta) \bar{y}-(1-\delta) u_{t}}{\theta+(1-\delta)^{2}} & \text { if } u_{t} \leq \underline{u} \\ \pi_{t}^{e} & \text { if } \underline{u} \leq u_{t} \leq \bar{u} \\ \frac{\pi_{t}^{e}+\bar{y}-u_{t}}{\theta+1} & \text { if } u_{t} \leq \bar{u}\end{cases}
$$

From this expression of the reaction function, we can reach our first two propositions: ${ }^{4}$

Proposition 1: The authorities do not accommodate small shocks.

Proof: From (7) it is clear that whenever $u_{t} \in[\underline{u} ; \bar{u}]$, there is no unexpected inflation and the authorities therefore do not absorb the supply shock, which proves proposition 1.

Proposition 2: The authorities accommodate large inflationary output shocks more than large recessionary shocks.

Proof: By plugging the relevant part of (7) in (3), one obtains the actual value of output for a given expected inflation rate when the authorities behave according to their reaction function. It amounts to $y_{t}=\frac{-\theta(1-\delta) \pi_{t}^{e}+(1-\delta)^{2} \bar{y}}{\theta+1}-\frac{\theta}{\theta+(1-\delta)^{2}} u_{t}$ whenever $\quad u_{t}<\underline{u} \quad$ and to $y_{t}=\frac{-\theta \pi_{t}^{e}+\bar{y}}{\theta+1}-\frac{\theta}{\theta+1} u_{t}$ whenever $u_{t}>\bar{u}$. The coefficient on $u_{t}$ indicates the elasticity of output to the initial shock. As $\delta$ is positive and smaller than one, it appears that the absolute elasticity of output to shock $u_{t}$ is greater when the shock is negative than when it is positive, which proves proposition (2).

The intuitive explanations of proposition 1 and 2 are easily grasped by looking at figure 2 below.

\footnotetext{
${ }^{4}$ This reaction function may be reminiscent of the discrete reaction functions assumed in escape clause models, such as Flood and Isard (1989) or Lohmann (1990). However, unlike in those models, the authorities' discrete response is fully endogenous in our analysis.
} 
$* * *$ insert figure 2 here $* * *$

Figure 2 features five different kinked supply functions for a given level of expected inflation $\pi^{e}$ and five different values of the supply shock $u_{t}$, such that $u_{t}>\bar{u}, u_{t}=\bar{u}, u_{t}=0, u_{t}=\underline{u}$ and $u_{t}<\underline{u}$. The indifference curves corresponding to each equilibrium are also represented. They are turned towards the authorities' bliss point $B$ whose abscissa is zero and ordinate $\bar{y}$, which are respectively their target levels of inflation and output.

Whenever the shock is positive and large, i.e. whenever $u_{t}>\bar{u}$, the authorities' optimal response is to accommodate the shock by implementing an inflation rate that lies below the expected one. That situation corresponds to point $E_{l}$ in figure 2. By the same token, if the output shock is very recessionary, i.e. $u_{t}<\underline{u}$, the authorities will create unexpected inflation to boost output, as one can see at point $E_{5}$.

If the shock is of limited magnitude, i.e. $\underline{u} \leq u_{t} \leq \bar{u}$, we obtain corner solutions, since the supply curve is kinked. Therefore the authorities do not find it optimal to react to the shock, which means that they set $\pi_{t}=\pi^{e}$ and thereby validate the private sector's expectations. In other words they choose the monetary policy that corresponds to the kink in the supply function. This is for instance the case at point $E_{3}$, where the shock is equal to zero. As a consequence, the observed level of output is simply equal to the value of the shock, since the natural level of output is equal to zero.

The trigger values of the output shock can easily be observed graphically. They correspond to the values of the supply shock for which the slope of the authorities' indifference curve is equal to the slope of the lower (respectively upper) part of the corresponding supply function exactly on its kink, as shown at points $E_{2}$ and $E_{4}$. It takes a larger shock to move the supply function beyond those trigger points and drive the optimal inflation rate above or below its expected level, as at point $E_{1}$ and $E_{5}$, which is the substance of proposition 1.

Figure 2 also helps capturing the intuition of our second proposition. The abscissa of point $Q_{5}$ shows the level of output that would have been obtained if the central bank had refrained from 
accommodating a shock that would have driven the supply curve to $S_{5}$. The difference between the abscissas of point $Q_{5}$ and $E_{5}$ therefore represents the stabilization achieved by monetary policy. By the same token, the difference between the abscissas of point $E_{1}$ and point $Q_{1}$ measures the stabilization achieved by monetary policy in the presence of a positive shock of similar magnitude that would have driven the supply curve to $S_{l}$. It is readily observed that stabilization is greater for the positive shock than for the negative one, which corresponds to our second proposition.

This result stems from the fact that the authorities determine the inflation rate by comparing the marginal loss incurred by increased inflation to the marginal benefit from bringing output closer to its target level. As wages are indexed upward but not downward, the marginal benefit of manipulating inflation is smaller for negative output shocks, that require to inflate more than expected and face wage indexation, than for positive output shocks that require to inflate less than expected. Therefore the incentive to manipulate inflation is smaller for negative shocks than for positive shocks. The former are consequently less accommodated than the latter.

The results we have obtained so far do not necessitate to determine expected inflation. However, determining expected inflation is a necessary step to complete the description of the outcome of monetary policy in our model. We turn to that step in the next section.

\section{Expectations, Output and Welfare}

When private agents form they expectations about the inflation rate, they do not know the magnitude of the inflation rate. They therefore ignore if the authorities will manipulate inflation and how. They must consequently expect an average of the conditional expectations of the inflation rates weighted by their probabilities. Accordingly, the private sector rationally expects the inflation rate that solves the following equation:

$\pi_{t}^{e}=\operatorname{prob}\left(u_{t}<\underline{u}\right) \cdot E\left(\pi_{t} \mid u_{t}<\underline{u}\right)+\operatorname{prob}\left(\underline{u}<u_{t}<\bar{u}\right) \cdot E\left(\pi_{t} \mid \underline{u}<u_{t}<\bar{u}\right)+\operatorname{prob}\left(u_{t}>\bar{u}\right) \cdot E\left(\pi_{t} \mid u_{t}>\bar{u}\right)$

The first step in solving equation (8) is to compute the conditional expectations and probabilities of the inflation rate, which requires to specify the distribution of $u_{t}$. In the rest of the paper, we assume therefore that it is normally distributed around zero. For conciseness sake, the conditional probabilities and expectations are defined in appendix (A2). By substituting those values in expression (8) and by simplifying, one obtains an equation whose solution is the expected inflation 
rate. Unfortunately, that equation is quite messy and has no simple solution. In the rest of this paper, we therefore resort to simulations to close the model.

$$
\text { ****Insert table } 1 \text { here*** }
$$

Table 1 reports the results of our simulations for a realistic range of the parameters. It exhibits the expected value of the inflation rate, of output and of the authorities' losses. It also displays the inflation rate and the losses that would be expected if wage indexation was symmetric, that are denoted $\pi_{\text {sym }}^{e}$ and $E\left(l_{\text {sym }}\right)$, and with no indexation, that are designated by $\pi^{e}{ }_{\text {noindex }}$ and $E\left(l_{\text {sym }}\right) .{ }^{5}$ It is noteworthy that expected output in the presence of symmetric indexation, or in the absence of indexation, is always equal to the natural level of output, which is zero in our set-up. It is therefore not reported in table 1.

Although the results displayed in table 1 rest on a simulation and cannot therefore be generalized, two important findings that are summarized in our next propositions are worth underlining.

Proposition 3a : Asymmetric wage indexation can be recessionary.

Proposition 3b : Asymmetric wage indexation can be expansionary.

\footnotetext{
${ }^{5}$ The inflation rates are given by $\pi_{\text {sym }}^{e}=\frac{1-\delta}{\theta} \bar{y}$ and $\pi_{\text {noindex }}^{e}=\frac{1}{\theta} \bar{y}$ respectively. Similarly, expected losses are $E\left(l_{\text {sym }}\right)=\frac{1}{2}\left[\frac{\theta}{(1-\delta)^{2}+\theta} \sigma^{2}+\frac{(1-\delta)^{2}+\theta}{\theta} \bar{y}^{2}\right]$ and $E\left(l_{\text {noindex }}\right)=\frac{1}{2}\left(\frac{\theta}{1+\theta} \sigma^{2}+\frac{1+\theta}{\theta} \bar{y}^{2}\right)$.
} 
That striking feature of our simulations is obtained by reading the sixth column of table 1 and appears in lines (1), (2), and (4) to (13). The intuition of this result rests on proposition 2. As the authorities absorb positive shocks more than negative ones, it is possible that output lies on average below its natural level. It need not be so though. Thus, this finding depends on the magnitude of the shocks that are stabilized and on the probability that they occur, which explains why expected output may also lie above its natural level, as in line (3) of table 1.

A slightly more careful inspection of table 1 reveals a second set of noteworthy findings that are summarized in proposition $4 \mathrm{a}$ and $4 \mathrm{~b}$.

Proposition 4a: Asymmetric wage indexation can reduce the inflationary bias relative to a situation without indexation.

Proposition 4b: Asymmetric wage indexation can reduce the inflationary bias relative to an equivalent symmetric indexation.

Proposition 4a is obtained by comparing columns (5) and (10) of table 1. It appears that the inflationary bias, alternatively expected inflation is systematically lower in the presence of asymmetric wage indexation than in the presence of no indexation at all. This finding is in line with the common view of the consequences of wage indexation on monetary policy, which can for instance be traced back to Devereux (1987). It results from the fact that wage indexation lowers the perceived benefits from unexpected inflation because it reduces its impact on the real wage. The temptation to inflate is therefore cut down accordingly.

Proposition $4 \mathrm{~b}$ is more innovative. It is obtained by comparing columns (5) and (8) of table 1. It underlines that there is more to asymmetric indexation than a simple combination of symmetric indexation and no indexation. To grasp the rationale behind that proposition, one must bear in mind that we are dealing with a stochastic model and that wage indexation interacts with both the deterministic component of the inflation rate and its stochastic component. Namely it reduces the inflationary bias but also modifies the way in which the authorities adjust the inflation rate so as to absorb output shocks.

By contrast, when indexation is symmetric, it cuts down the inflationary bias but has a symmetric impact on the reaction of the authorities to output shocks. In other words it reduces the 
incentives to engineer unexpected inflation but also unexpected disinflation, when shocks are very expansionary. On average, both effects cancel out.

When indexation is asymmetric however, it also cuts down the inflationary bias but it only reduces the incentive to create unexpected inflation and leaves intact the incentive to create unexpected disinflation. This asymmetry in the reaction of the authorities to output shocks further reduces the average inflation rate, which explains why expected inflation is even smaller than in the presence of symmetric wage inflation.

One may now wonder what the previous results imply for the welfare effects of wage indexation. Table 1 also provides some insights on that issue, that are described in our final propositions:

Proposition 5a: Asymmetric wage indexation can improve expected welfare relative to a situation without indexation.

Proposition 5b: Asymmetric wage indexation can improve expected welfare relative to an equivalent symmetric indexation.

The finding described by proposition 5a is obtained by comparing column 7 and column 11 of table 1. A quick glance at those two columns reveals that expected losses are smaller under asymmetric wage indexation than in the absence of indexation. That observation is quite in line with the standard results of the literature. It is for instance at the core of Devereux (1987)'s analysis and is also investigated by Milesi-Ferretti (1994). It basically stems from the fact that, even though it may result in larger output volatility, wage indexation cuts down the inflationary bias of monetary policy. Therefore, if the benefit of reducing inflation outweighs the cost of increasing the volatility of output, wage indexation can improve welfare.

Proposition 5b, which states that the welfare-improving property of asymmetric wage indexation can exceed that of an equivalent symmetric indexation, is somewhat subtler than proposition 5a. It is obtained by comparing column 7 and column 9 of table 1 which shows that expected losses are consistently smaller in the former. To grasp the rationale for that finding, one has to bear in mind that if asymmetric indexation may come at the cost of a smaller expected level of output, it also has two advantages relative to an equivalent symmetric indexation. Namely, as 
proposition $4 \mathrm{~b}$ underlines, asymmetric wage indexation firstly reduces expected inflation more than an equivalent symmetric indexation. Secondly, it does not affect output stabilization as much as its symmetric equivalent. To be precise, symmetric wage indexation reduces the marginal benefit of manipulating inflation both in the presence of positive and negative output shocks. On the other hand, asymmetric wage indexation only affects the marginal benefit of accommodating large negative output shocks, but leaves unchanged the incentive to absorb positive shocks. The very mechanism that accounts for the negative impact of asymmetric wage indexation on expected output is consequently also the one that accounts for its superiority over symmetric wage indexation in terms of welfare, since monetary authorities are averse to output fluctuations.

\section{Concluding remarks}

In this paper, we studied the consequences of asymmetric wage indexation for monetary policy in a framework à la Barro and Gordon (1983). We observed that that marginal modification of their framework provides unexpected modifications of the usual findings of the literature. Namely, we found that the reaction of monetary authorities to output shocks could become asymmetric, leading to an expected level of output that may be below its natural level. We also found that if wage indexation is deflationary, it is more so when it is asymmetric. Finally, we observed that asymmetric wage indexation could be superior to symmetric wage indexation in terms of welfare. A synthetic theoretical implication of our findings is that making our models slightly more realistic can significantly alter the results that are usually considered standard in the literature.

The main policy implication of our results is that wage indexation is more subtle a policy instrument and that its effects are more pervasive than what is usually contended in the literature. Owing to the complexity of our calculations, we had to resort to numerical simulations and cannot unfortunately be more specific as to the critical values of the parameters. Our results accordingly deserve closer examination, which paves the way for future research. However, in the mean time, they remain, to say the least, intriguing. 


\section{Appendix}

\section{A1 Monetary policy when $u_{t} \in[u ; \bar{u}]$}

In this appendix, we show that the optimal monetary policy when $u_{t} \in[u ; \bar{u}]$ consists in validating the private sector's expectations. Our line of reasoning is organized in two steps. We firstly show that it is not optimal for the authorities to implement an inflation rate that exceeds expected inflation. We then show that it is not optimal to implement an inflation rate that is lower than expected inflation.

Let us assume that the authorities implement an inflation rate that exceeds expected inflation. Under those circumstances, wages are indexed and the supply function is given by (3). To determine the optimal inflation rate, we plug (3) in (4) and differentiate. We thus get the following expression:

$$
\left.\frac{\partial l}{\partial \pi_{t}}\right|_{\delta \in[0 ; 1]}=(1-\delta)^{2}\left(\pi_{t}-\pi_{t}^{e}\right)+(1-\delta)\left(\bar{y}-u_{t}\right)+\theta \pi_{t}
$$

As we assume that the inflation rate that the authorities implement is greater than the expected inflation rate, it is clear that the first member of expression (A1) is positive. It can easily be shown that the second member of that expression is also positive. Thus, as we assume that $u_{t} \in[u ; \bar{u}]$, we know from (6a) that $u_{t}>\bar{y}-\frac{\theta}{1-\delta} \pi_{t}^{e}$. This is equivalent to:

$$
(1-\delta)\left(u_{t}-\bar{y}\right)>-\theta \pi_{t}^{e}
$$

By adding $\theta \pi_{t}$ to both sides of the above inequality and factorizing, one finds:

$$
(1-\delta)\left(u_{t}-\bar{y}\right)+\theta \pi_{t}>\theta\left(\pi_{t}-\pi_{t}^{e}\right)>0
$$

As we assume that $\pi_{t}>\pi_{t}^{e}$, expression (A3), that is equal to the second part of expression (A1), is clearly positive, meaning that the authorities' losses are increasing in $\pi_{t}$. The authorities' optimal solution is consequently a corner solution and they set $\pi_{t}=\pi_{t}^{e}$.

By the same token, we can show that the authorities will not set an inflation rate that is lower than expected. Under those circumstances, wages are not indexed and the supply function is given by (3) with $\delta=0$. To determine the optimal inflation rate, we plug (3) in (4) and differentiate. We thus get the following expression: 


$$
\left.\frac{\partial l}{\partial \pi_{t}}\right|_{\delta=0}=\pi_{t}-\pi_{t}^{e}-\bar{y}+u_{t}+\theta \pi_{t}
$$

As we assume that the inflation rate that the authorities implement is smaller than the expected inflation rate, it is clear that the first member of expression (A4) is negative. It can easily be shown that the second member of that expression is also negative. Thus, as we assume that $u_{t} \in[u ; \bar{u}]$, we know from (6a) that $u_{t}<\bar{y}-\theta \pi_{t}^{e}$, which is equivalent to:

$$
u_{t}-\bar{y}<-\theta \pi_{t}^{e}
$$

By adding $\theta \pi_{t}$ to both sides of the above inequality and factorizing, one finds:

$$
u_{t}-\bar{y}+\theta \pi_{t}<\theta\left(\pi_{t}-\pi_{t}^{e}\right)<0
$$

As we assume that $\pi_{t}<\pi_{t}{ }^{e}$, expression (A6) shows that the second member of expression (A4) is clearly negative, meaning that the authorities' losses are decreasing in $\pi_{t}$. The authorities' optimal solution is consequently a corner solution and they set $\pi_{t}=\pi_{t}^{e}$.

Consequently, whenever $u_{t} \in[u ; \bar{u}]$, the authorities' optimal policy is to implement the inflation rate that was expected by the private sector. They consequently do not accommodate the supply shock.

\section{A2 Conditional expectations and probabilities}

As $u_{t}$ follows a normal distribution, the conditional probabilities on $u_{t}$ can be written as:

$$
\begin{aligned}
& \operatorname{prob}\left(u_{t}<\underline{u}\right)=\int_{-\infty}^{u} f d u \quad \operatorname{prob}\left(\underline{u}<u_{t}<\bar{u}\right)=\int_{\underline{u}}^{\bar{u}} f d u \quad \operatorname{prob}\left(u_{t}>\bar{u}\right)=\int_{\bar{u}}^{\infty} f d u \\
& \text { (A7a) } \\
& \text { (A7c) }
\end{aligned}
$$

where $f=\frac{1}{\sigma \sqrt{2 \pi}} e^{-\frac{u^{2}}{2 \sigma^{2}}}$ is the normal density function.

By the same token, the conditional expectation of the inflation rate can be written as:

$$
\begin{aligned}
& E\left(\pi_{t} \mid u_{t}<\underline{u}\right)=\int_{-\infty}^{\underline{u}} f \cdot \pi_{t} \mid u_{t}<\underline{u} d u \\
& E\left(\pi_{t} \mid \underline{u}<u_{t}<\bar{u}\right)=\int_{\underline{u}}^{\bar{u}} f \cdot \pi_{t} \mid \underline{u}<u_{t}<\bar{u} d u
\end{aligned}
$$




$$
E\left(\pi_{t} \mid u_{t}>\bar{u}\right)=\int_{\bar{u}}^{\infty} f \cdot \pi_{t} \mid u_{t}>\bar{u} \quad d u
$$




\section{References}

Ball L., Cecchetti, S., 1991. Wage indexation and discretionary monetary policy, American Economic Review 81, 1310-1319.

Barro R., Gordon, D., 1983. A positive theory of monetary policy in a natural rate model, Journal of Political Economy 91, 589-610.

Card D., 1986. An empirical model of wage indexation provisions in union contracts, in wage indexation, Journal of Political Economy 94, 3, 144-175.

Clarida R., Gertler, M., 1997. How the Bundesbank conducts monetary policy, in D. Romer (ed): Reducing inflation, University of Chicago Press, Chicago.

Cover J.P., 1992. Asymmetric effects of positive and negative money supply shocks, Quarterly Journal of Economics 107, 1261-1282.

Cover J.P., VanHoose, D.D., 2002. Asymmetric wage indexation, Atlantic Economic Journal 30, $34-47$.

Cukierman, A., 2000. The inflation bias result revisited, Manuscript, Tel-Aviv University.

Cukierman, A., Gerlach, S., 2002. The inflation bias result revisited: Theory and some international evidence, Mimeo.

Devereux, M., 1987. The effect of monetary variability on welfare in a simple macroeconomic model, Journal of Monetary Economics 19, 427-435.

Dolado, J.J., Maria Dolores, R., Naveira, M., 2000. Asymmetries in monetary policy rules: Evidence for four central banks, CEPR, Discussion paper, 2441.

Flood, R.P., Isard, P., 1989. Monetary Policy Strategies. IMF Staff Papers 36, 612-632.

Gerlach, S., 2000. Asymmetric policy reactions and inflation, Manuscript, Bank of International Settlement.

Gray, J.A., 1976. Wage indexation: a macroeconomic approach, Journal of Monetary Economics $2,221-235$.

Jordan, T.J., 2001. Monetary Control Uncertainty and Inflation Bias, Journal of Economics, 73, 2, 125-147.

Kandil, M., 1995. Asymmetric nominal flexibility and economic fluctuations, Southern Economic Journal 61, 674-695. 
Kandil, M., 1998. Supply-side asymmetry and the non-neutrality of demand fluctuations, Journal of Macroeconomics 20, 785-809.

Kandil, M., 2002. Asymmetry in economic fluctuations in the US economy, International Economic Journal 16, 21-42.

Lohmann, S., 1990. Monetary Policy Strategies - a Correction: Comment on Flood and Isard. IMF Staff Papers 37, 612-632.

Milesi-Ferretti, G.M., 1994. Wage indexation and time consistency, Journal of Money Credit and Banking 26, 941-950.

Mishkin, F., Posen, A., 1997. Inflation targeting: lessons from four countries, Federal Reserve of New York Economic Policy Review 3.

Sorico, P., 2002. US Monetary policy rules: the case for asymmetric preferences, Fondazione Eni Enrico Mattei Note di Lavoro, 66, 2002.

VanHoose, D.D., Waller, C.J., 1991. Discretion, wage indexation and inflation. Southern Economic Journal 58: 356-367.

VanHoose, D.D., Waller, C.J., 1992. Discretionary monetary policy and socially efficient wage indexation. Quarterly Journal of Economics 107: 1451-1460. 
Figure 1

Time sequence of events

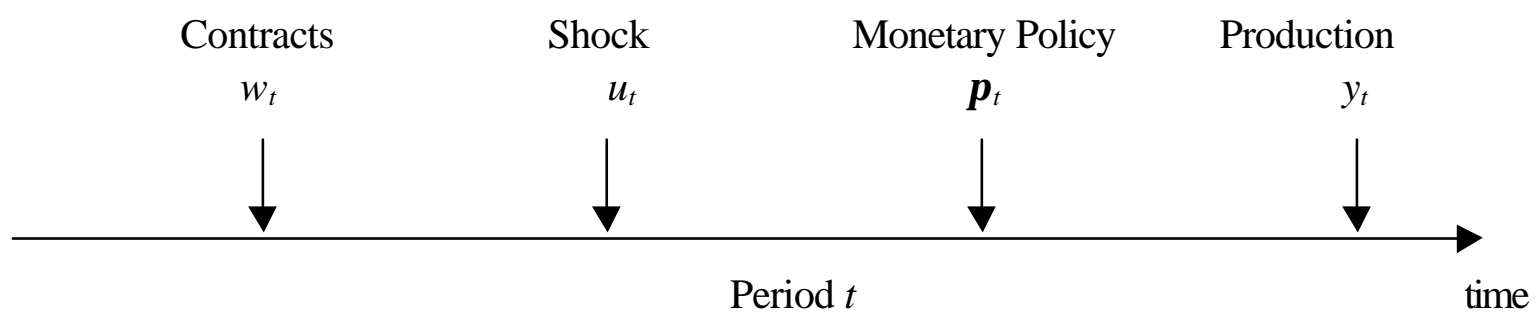


Figure 2

The authorities' response to shocks

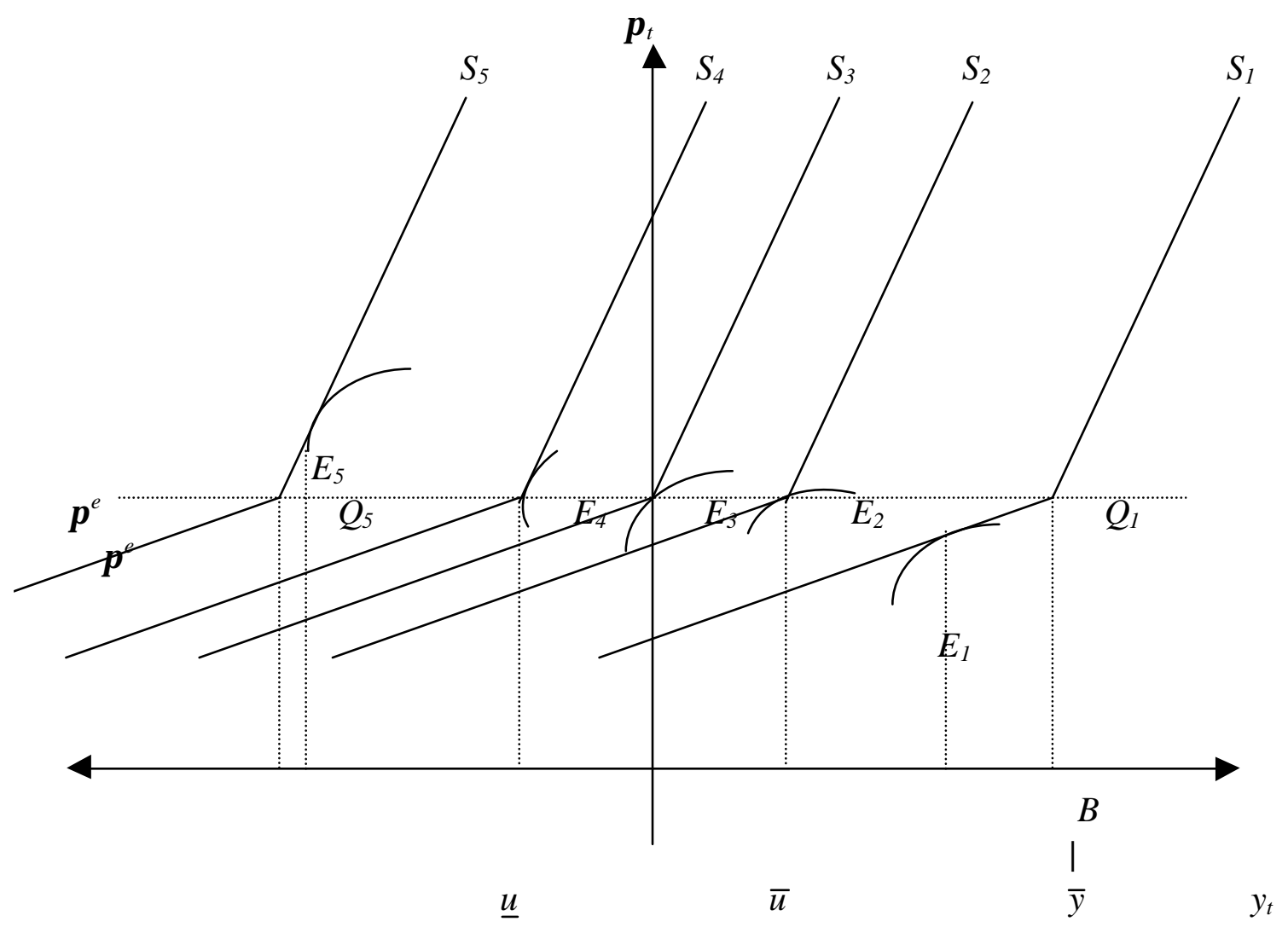


Table 1 : simulation results

\begin{tabular}{|c|c|c|c|c|c|c|c|c|c|c|c|}
\cline { 2 - 13 } \multicolumn{1}{c|}{} & \multicolumn{4}{|c|}{ Parameters } & \multicolumn{3}{c|}{ Asymmetric indexation } & \multicolumn{2}{c|}{$\begin{array}{c}\text { Symmetric } \\
\text { indexation }\end{array}$} & \multicolumn{2}{c|}{ No indexation } \\
\cline { 2 - 14 } & $(1)$ & $(2)$ & $(3)$ & $(4)$ & $(5)$ & $(6)$ & $(7)$ & $(8)$ & $(9)$ & $(10)$ & $(11)$ \\
\cline { 2 - 14 } \multicolumn{1}{c|}{} & $\sigma$ & $\bar{y}$ & $\theta$ & $\delta$ & $\pi^{e}$ & $E(y)$ & $E(l)$ & $\pi_{\text {sym }}^{e}$ & $E\left(l_{\text {sym }}\right)$ & $\pi_{\text {noindex }}^{e}$ & $E\left(l_{\text {noindex }}\right)$ \\
\hline$(1)$ & 1 & 1 & 1 & 0.5 & 0.323 & -0.096 & 0.577 & 0.5 & 1.025 & 1 & 1.25 \\
\hline$(2)$ & 1 & 1 & 1 & 0.9 & 0.070 & -0.170 & 0.589 & 0.1 & 1 & 1 & 1.25 \\
\hline$(3)$ & 1 & 1 & 1 & 0.1 & 0.474 & 0.040 & 0.558 & 0.9 & 1.181 & 1 & 1.25 \\
\hline$(5)$ & 1 & 1 & 0.5 & 0.5 & 0.670 & -0.046 & 0.567 & 1 & 1.083 & 2 & 1.667 \\
\hline$(6)$ & 1 & 1 & 2 & 0.5 & 0.166 & -1.222 & 0.586 & 0.25 & 1.007 & 0.5 & 1.083 \\
\hline$(7)$ & 1 & 1 & 5 & 0.5 & 0.067 & -0.139 & 0.595 & 0.1 & 1.001 & 0.2 & 1.017 \\
\hline$(8)$ & 1 & 0.5 & 1 & 0.5 & 0.151 & -0.076 & 0.279 & 0.25 & 0.556 & 0.5 & 0.5 \\
\hline$(9)$ & 1 & 2 & 1 & 0.5 & 0.717 & -0.091 & 1.777 & 1 & 2.9 & 2 & 4.25 \\
\hline$(10)$ & 1 & 4 & 1 & 0.5 & 1.607 & -0.031 & 6.947 & 2 & 10.4 & 4 & 16.25 \\
\hline$(11)$ & 0.5 & 1 & 1 & 0.5 & 0.358 & -0.045 & 0.444 & 0.5 & 0.725 & 1 & 1.063 \\
\hline$(12)$ & 1.5 & 1 & 1 & 0.5 & 0.311 & -0.125 & 0.805 & 0.5 & 1.525 & 1 & 1.563 \\
\hline$(13)$ & 2 & 1 & 1 & 0.5 & 0.302 & -0.151 & 1.116 & 0.5 & 2.225 & 1 & 2 \\
\hline
\end{tabular}

